\title{
Purulent Hydroaeric Pleural Effusion Due to Infection with Gemella morbillorum: A Case Report
}

\author{
Hind Serhane, Hafsa Sajiai, Anas Arrad, Selma Ait Batahar, Lamyae Amro, \\ Abdelhaq Alaoui-Yazidi \\ Department of Respiratory Medicine, Laboratory PCIM, Faculty of Medicine and Pharmacy, Cadi Ayyad \\ University, Marrakesh, Morocco \\ Email: hindserhane8@gmail.com
}

Received 15 September 2014; revised 10 October 2014; accepted 4 November 2014

Copyright (C) 2014 by authors and Scientific Research Publishing Inc.

This work is licensed under the Creative Commons Attribution International License (CC BY). http://creativecommons.org/licenses/by/4.0/

(c) (i) Open Access

\begin{abstract}
Gemella morbillorum (G. morbillorum) is an opportunistic bacterium, which can sometimes cause severe infections especially in immunocompromised subjects. Respiratory infections due to this germ are rare, but are described. We reported a new observation of 34-year-old female patient, admitted for unusual location and clinical presentation of respiratory infection with $G$. morbillorum; she was presented a left pleuritic pain, a productive cough associated with purulent and foul sputum and dyspnea with onset one month earlier. The clinical examination was objectified a polypnea at 32 cycles/minutes, intercostal indrawing and mixed pleural effusion syndrome. She had also many dental caries and bad oral health status. Chest radiography showed an air-fluid image in the left chest and the thoracocentesis had revealed purulent fluid. The culture of this fluid had isolated a G. morbillorum. The diagnosis of mixed pleural effusion due to G. morbillorum in an immunosuppressed diabetic patient was made. The patient was put on antibiotics, thoracic drainage and Chest physiotherapy with good improvement.
\end{abstract}

\section{Keywords}

Gemella morbillorum, Gemella Species, Respiratory Infection, Hydroaeric Pleural Effusion

\section{Introduction}

G. morbillorum is a bacterium belonging to the family of the Gemella species. These microorganisms are gram positive cocci and facultative anaerobes which—like other human commensal bacteria-are opportunistic 
pathogens and may cause serious local and systemic infection, mainly in immunodepressed patients [1]. It can cause endocarditis [2], septic artritis [3], and meningitis [4]. It is an infrequently isolated organism and a rare cause of pulmonary and pleural infection. But, some cases of lung abscesses [5], necrotising pneumonia [6] [7] and pleural empyemas [8] have been reported in the literature. The prognosis of this infection will depend on the location, but also on the field of patient. So, some locations, such as cerebral localization are worse prognosis reports to others [9]. The pleura and lung manifestations of this infection have rarely been described. We present a new observation of purulent hydroaeric pleural effusion caused by this microorganism.

\section{Case Report}

A 34-year-old woman, non-smoker, diabetic type I, never treated for tuberculosis (TB) and without TB recent contagion. She was admitted for left-sided pleuritic pain following a cooling episode, a productive cough associated with purulent and foul sputum, a dyspnea on the slightest exertion, in a context of preservation of the general state, with onset one month earlier. The patient was treated in a local hospital, with probabilistic antibiotics amoxicillin-clavulanic acid for 15 days but without improvement and she was then transferred to our hospital. On admission, her body temperature was $37.2^{\circ} \mathrm{C}$. Of note in her clinical examination was a polypnea at 32 cycles/minutes, intercostal indrawing, symptoms of left mixed pleural effusion. She had also many dental caries and bad oral health status. A chest X-ray showed dense opacity, with water tonality which sits at the left lower lobe with air-fluid level (Figure 1). C-reactive protein (CRP) was $382 \mathrm{mg} / \mathrm{l}$ without high total leukocytes count. A lymphopenia at 600 elements $/ \mathrm{mm}^{3}$ was noted. The search for Mycobacterium tuberculosis (BK) on direct microscopic examination and the HIV serology were negatives. Diagnostic thoracocentesis was performed. Purulent, greenish, putrid fluid was obtained. Culture of this fluid revealed the growth of G moribillorum with reduced susceptibility to penicillin but susceptible to cephalosporins. Chest computerized tomography (CT) shows abundant mixed left pleural effusion with ipsilateral lung collapsed (Figure 2). The bronchoscopy had objectified a diffuse inflammatory bronchial mucosa with release of purulent secretions. The treatment commenced with a chest drain (total volume $2300 \mathrm{ml}$ ), and ceftriaxone at dose of $2000 \mathrm{mg}$ every 24 hours intravenously with relay by oral treatment 4 days later, as well as gentamicin (160 mg every 24 hours, intravenously) for 5 days, oral metronidazole (500 mg every 8 hours) and chest physiotherapy was then added, with good clinical outcome; degreased chest pain, disappearance and clarification of purulent sputum. The CRP had decreased to $28 \mathrm{mg} / \mathrm{l}$,

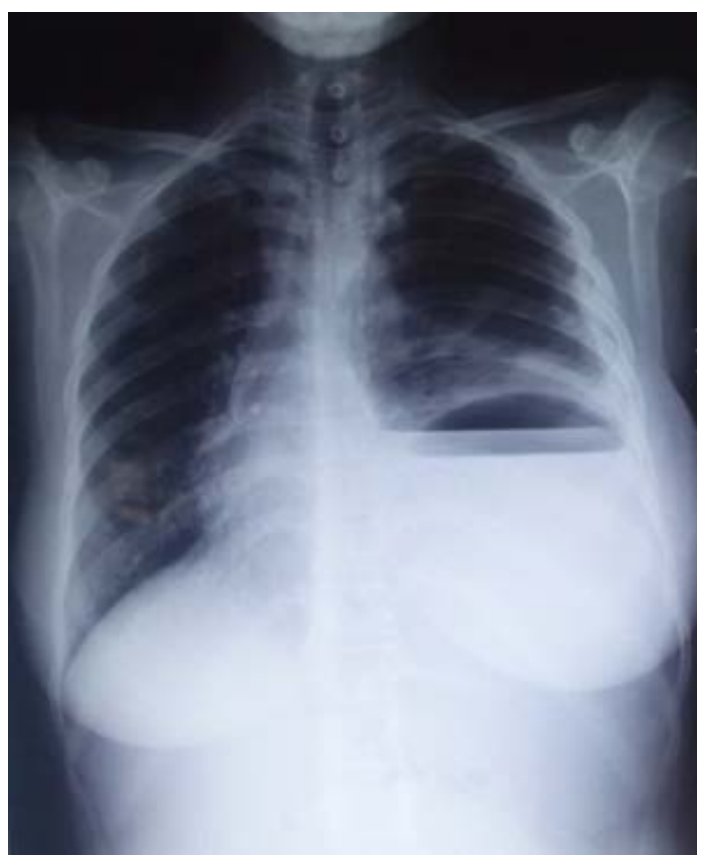

Figure 1. Face chest radiography showing dense pleural opacity, with water tonality witch sits at the left lower lobe with air-fluid level. 


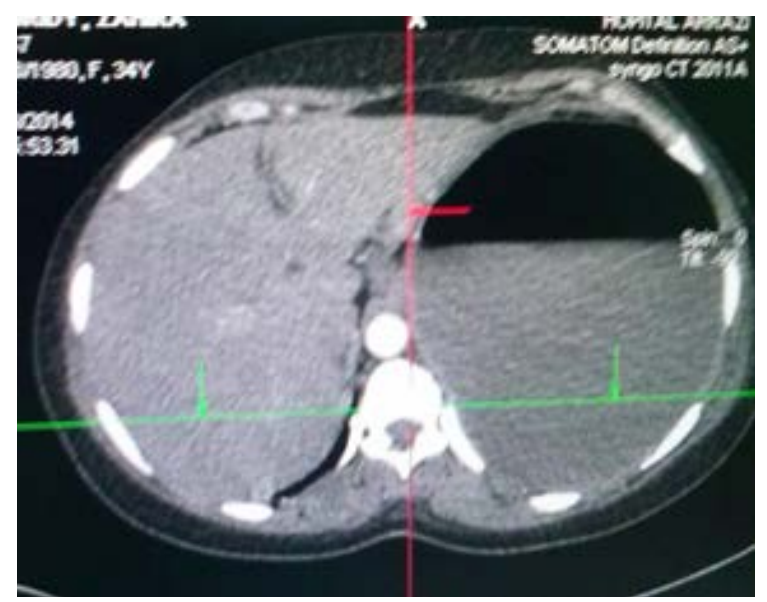

Figure 2. Transversal scannographic section objectifying a hydroaeric image with ipsilateral lung collapsed.

and lymphopénia increased to 1600 elements $/ \mathrm{mm}^{3}$. Radiologically, an improvement also was noted, with disappearance of the air-fluid level and top ventilation of the lung parenchyma.

\section{Discussion}

G. morbillorum, isolated in 1917 from blood of patients with measles [9], was transferred from the genus Streptococcus to the genus Gemella (also including Gemella haemolysans and several recently described organisms). It is an aerobic or aerotolerant Gram-positive coccus usually found in pairs, which explains the name of this genus. Underlying conditions (e.g. immunocompromission, cancer, heart disease, sinusitis or poor dental condition, as well as previous invasive medical procedures) are frequently, but not necessarily [10], associated with human infections caused by G. morbillorum, and some reported cases in previously healthy people suggest that its pathogenicity should not be underestimated [10] [11]. Although it is generally susceptible to penicillin and other antibiotics, resistance to penicillin, has been reported [11], as the case of our patient. Due to their opportunistic nature, these species are capable of causing certain infections, the most common of which are septicaemia [12], infections of the nervous system [4], arthritis [3], liver abscesses [13], and endocarditis [2]. Many cases of respiratory tract infections have been described such as necrotizing pneumonia [6] [7] [9] lung abscesses [5] and even colonization of the tuberculous cavity. However, the appearance of pleural involvement is considered exceptional [1]. In a revue of medical litterature, we identified 15 cases of pleural empyema caused by Gemella species [1] [6] [14]-[18], published mostly by spanish teams. Thus, García-Lechutz et al. [18] had described 4 cases of pleural empyema caused by Gemella species over a period of 4 years. Also, 4 other cases have been published over a period of 7 years by the pulmonology department of the university hospital of valencia, a case has been published separately by Signes-Costa [6] and 3 other cases have been reported after by Senent [1], but to the best of our knowledge, the purulent hydro-aeric pleural effusion caused by this germ has never been reported.

Among the underlying conditions presented by patients with this type of infection intravenous drug addiction [8] [18], cardiovascular disease, alcohol abuse [18] and diabetes [18] are notable, as was the case in our patient from this study, infected by G morbillorum and diabetes. Predisposing factors include poor mouth hygiene and prior dental procedures, which due to the disruption in the mucosa, could facilitate hematogenous dissemination, as well as microaspiration of oropharyngeal secretions that would facilitate bronchogenic dissemination [1], which we believe could have occurred in this patient given the past medical history of poor oral health status. Penicillin or ampicillin are the drugs of choice for treating infections of gemella spices. However, occasional resistance to penicillin has been reported in rare cases, such as our patient, who was put under cephalosporin. Moreover, there is insufficient information on the duration of treatment and so it is recommended to prolong treatment for at least 4 weeks [6]. The management of these patients is based on drainage of the empyema with therapeutic thoracocentesis or chest drain. In our patient, we performed chest drain and antibiotic treatment was continued for 4 weeks with a satisfactory clinical and radiologic outcome. 


\section{Conclusion}

In the case of patient with pleural involvement, we must consider the possibility of infection caused by Gemella species, especially in immunodepressed patients or those having predisposing factors like poor dental health.

\section{Conflicts of Interests}

I declare that I have no conflict of interests here.

\section{References}

[1] Senent, C., Sancho, J.-N., Chiner, E., Signes-Costa, J., Camarasa, A. and Andreu, A.-L. (2008) Pleural Empyema Caused by Gemella Species: A Rare Condition. Arch Bronconeumol, 44, 574-77.

[2] Murai, M., Fukumoto, H., Negoro, N., Sano, N., Nishimoto, N., Muraoka, H., et al. (2006) Evidence of Active Endocarditis, Caused by Gemella morbillorum, Related to Acute Embolic Stroke. International Journal of Cardiology, 112, 17-18. http://dx.doi.org/10.1016/j.ijcard.2006.01.071

[3] Roche, M. and Smyth, E. (2005) A Case of Septic Arthritis Due to Infection with Gemella morbillorum. Journal of Infection, 51, 187-189. http://dx.doi.org/10.1016/j.jinf.2005.01.009

[4] Villegas, E., Valldeoriola, F., Otero, J., Ferrer, L., Oms, B., Vila, L., et al. (2008) Meningitis by Gemella morbillorum with Associated Pituitary Apoplexy: A Case Report. European Journal of Internal Medicine, 19, 101-102. http://dx.doi.org/10.1016/j.ejim.2008.07.003

[5] De Soyza, A., Higgins, B. and Gould, K. (2000) An Unusual Case of Pulmonary Abscess. Journal of Infection, 41, 114. http://dx.doi.org/10.1053/jinf.2000.0686

[6] Signes-Costa, J., Chiner, E. and Arriero, J.M. (2000) Neumonía necrosante y empiema por Gemella morbillorum en paciente laringuectomizado. Arch Bronconeumol, 36, 601-602.

[7] Famularo, G., de Simona, C., Minisola, G. and Nicotra, G.C. (2006) Pneumonia and Sepsis Caused by Gemella morbillorum: An Unusual Association. Internal Medicine, 45, 1253-1254. http://dx.doi.org/10.2169/internalmedicine.45.1792

[8] Valipour, A., Koller, H., Setinek, U. and Burghuber, O.C. (2005) Pleural Empyema Associated with Gemella morbillorum: Report of a Case and Review of the Literature. Scandinavian Journal of Infectious Diseases, 37, 378-381. http://dx.doi.org/10.1080/00365540510035319

[9] Messori, A., Bartolucci, F., Dini, M., Mataloni Paggi, A., Ricciuti, R., Rychlicki, F., et al. (2002) Gemella morbillorum Deep Brain Abscess Successfully Treated with Combined Stereotactic, Medical, and Imaging Approach. European Journal of Radiology, 44, 143-151. http://dx.doi.org/10.1016/S0720-048X(02)00006-2

[10] Estivals, M., Mermond, S., Barbe, C., Du Covedic, L., Birolleau, S. and Levenes, H. (2007) Pneumopathie nécrosante à Gemella morbillorum chez un patient immunocompétant. Revue des Maladies Respiratoires, 24, 1143-1146. http://dx.doi.org/10.1016/S0761-8425(07)74266-3

[11] Farmaki, E., Roilides, E., Darilis, E., Tsivitanidou, M., Panteliadis, C. and Sofianou, D. (2000) Gemella Morbillorum Endocarditis in a Child. Pediatric Infectious Disease Journal, 19, 751-753. http://dx.doi.org/10.1097/00006454-200008000-00015

[12] Vasishtha, S., Isenberg, H.D. and Sood, S.K. (1996) Gemella morbillorum as a Cause of Septic Shock. Clinical Infectious Diseases, 22, 1084-1086. http://dx.doi.org/10.1093/clinids/22.6.1084

[13] Nam, H.J., Yoon, S.J., John, B.M., Jung, S.H., Kim, A., Ko, B.S., et al. (2005) Liver Abscess Caused by Gemella Morbillorum. Korean Journal of Gastroenterology, 46, 56-59.

[14] da Costa, C.T., Porter, C., Parry, K., Morris, A. and Quoraishi, A.H. (1996) Empyema Thoracis and Lung Abscess Due to Gemella morbillorum. European Journal of Clinical Microbiology and Infectious Diseases, 15, 75-77. http://dx.doi.org/10.1007/BF01586189

[15] García del Busto, A., Moreno, R., Pardo, F. and Ferrándiz, A. (1995) Empiema causado por Gemella morbillorum. Med Clin (Barc), 104, 196-197.

[16] Hayashi, Y. and Ito, G. (1996) A Case of Bacterial Empyema Caused by Gemella morbillorum. Kansenshogaku Zasshi, 70, 259-263.

[17] Marcos Sánchez, F., Celdrán Gil, J., Árbol Linde, F. and Caballero Sánchez-Robles, L. (2000) Empiema pleural por Gemella morbillorum con una evolución favorable. Anales de Medicina Interna, 17, 112-113.

[18] García-Lechuz, J.M., Cuevas-Lobato, O., Hernangómez, S., Hermida, A., Guinea, J., Marín, M., et al. (2002) ExtraAbdominal Infections Attributable to Gemella Species. International Journal of Infectious Diseases, 1, 78-82. 
Scientific Research Publishing (SCIRP) is one of the largest Open Access journal publishers. It is currently publishing more than 200 open access, online, peer-reviewed journals covering a wide range of academic disciplines. SCIRP serves the worldwide academic communities and contributes to the progress and application of science with its publication.

Other selected journals from SCIRP are listed as below. Submit your manuscript to us via either submit@scirp.org or Online Submission Portal.
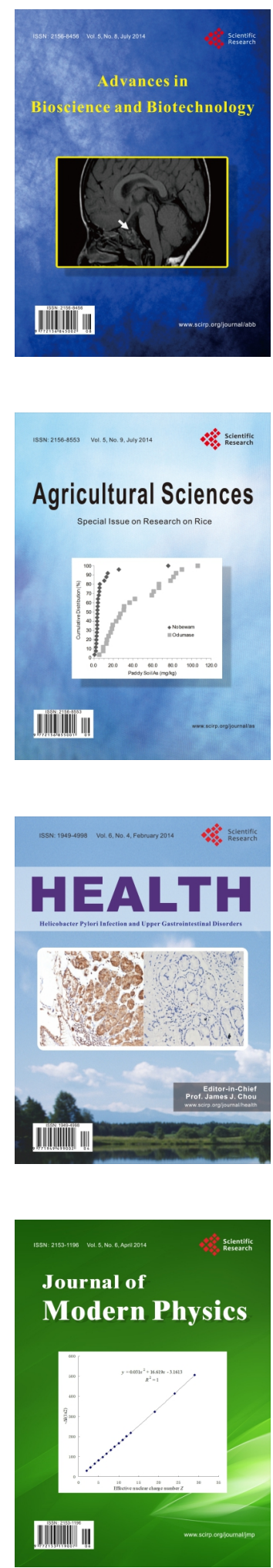
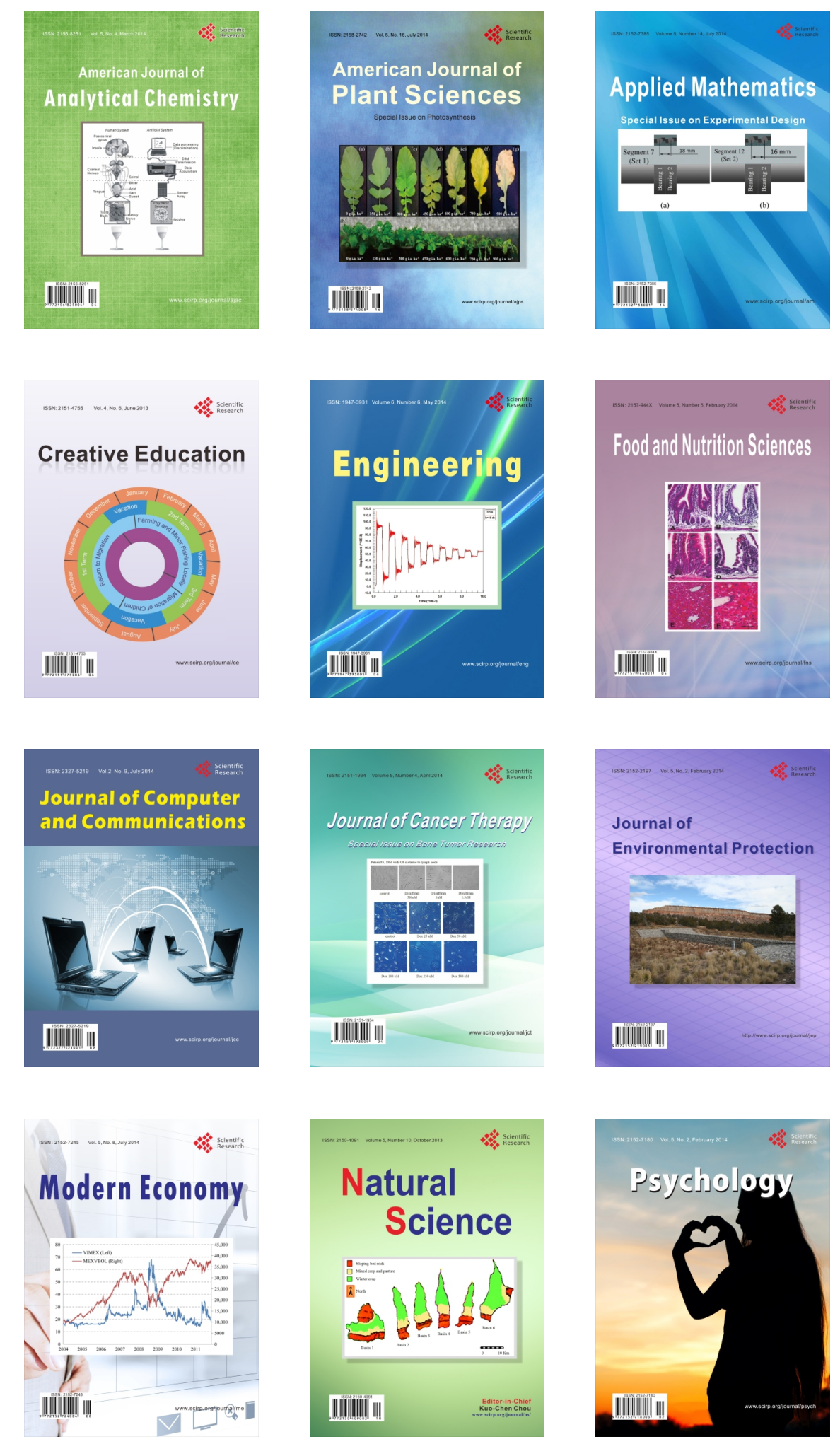